\title{
Dealing with uncertainty and risk in the design of deep and high stress mining excavations
}

WC Joughin SRK Consulting (South Africa) (Pty) Ltd, South Africa

\begin{abstract}
A method for risk-based design under high stress conditions is described in this paper. Probabilistic methods of analysis are applied to stress modelling to determine the probability of exceeding a given depth of failure. Suggestions are provided for dealing with geotechnical uncertainty. The understanding of aleatory variability can be improved by collecting more data and improving the quality of data through training and quality control. Stress and model uncertainty remain a challenge in geotechnical engineering. Some degree of subjective engineering judgement will therefore always be required in geotechnical design.

An economic risk model is used to determine the frequency and severity of the consequences of stress damage. The cost of rehabilitation of tunnels and the financial losses due to lost production are assessed using the model. A typical risk matrix is used to evaluate the level of risk. Different types of excavations have different risk profiles based on the potential impact on production. The design engineer can use the model to determine design criteria for stress damage. The risk can be mitigated through improved support or by changing the mining layout. These measures both have financial implications and the economic risk model is useful for decision making.
\end{abstract}

A brief discussion on risk-based design criteria for rockbursts is also included.

Keywords: risk-based design, probabilistic design, uncertainty

\section{Introduction}

In underground mines, the design engineer needs to deal with uncertainty in many forms. Uncertainty is commonly categorised as epistemic and aleatory. Baecher \& Christian (2003) describe aleatory uncertainty as random variations or the natural variability occurring in the world, while epistemic uncertainty represents the unknown, due to lack of knowledge. The sources of uncertainty include natural variability in rock mass properties, insufficient data, measurement errors, sampling bias, load uncertainty, model simplifications and assumptions (Hadjigeorgiou \& Harrison 2011; Contreras \& Ruest 2016; Brown 2012). The understanding of natural variability improves with more representative and better quality data, but dealing with epistemic uncertainty requires engineering judgement and experience. A high degree of epistemic uncertainty is expected in geotechnical design and therefore subjective engineering judgement is unavoidable.

The philosophy provided by Vick (2002) where he distinguishes between a 'relative frequency approach' and a 'subjective, degree of belief approach' is useful:

- Relative frequency approach: The probability of an uncertain event is its relative frequency of occurrence in repeated trials or experimental sampling of the outcome.

- Subjective, degree of belief approach: The probability of an uncertain event is the quantified measure of one's belief or confidence in the outcome, according to their state of knowledge at the time it is assessed.

Many powerful methods for evaluating uncertainty and probabilistic analysis of geotechnical stability have been developed over the years (Baecher \& Christian 2003; Harr 1996; Rosenblueth 1981; Rosenblueth 1975; Bradley 2007; Kroese \& Rubinstein 2012; Brown 2012; Contreras \& Ruest 2016) and there are several examples of application in slopes (Tapia et al. 2007; Steffen et al. 2008; Contreras 2015; Chiwaye \& Stacey 
2010; Wesseloo \& Read 2009; Terbrugge et al. 2006) and underground excavations (Valley et al. 2010; Lü \& Low 2011a; Lü et al. 2012; Lü \& Low 2011b; Langford \& Diederichs 2015; Joughin et al. 2012; Joughin et al. 2016; Abdellah et al. 2014; Joughin et al. 2000). Despite this, these methods are not widely applied in underground mining geotechnical design and deterministic methods are generally preferred. This is partly due to the additional effort required for probabilistic analyses and a lack of tools to make such analysis easily achievable on a mine site. Another stumbling block seems to be the lack of prescribed 'acceptable probabilities of failure' which serves as a design acceptance criteria.

Universal acceptance criteria are not useful, because the probability of failure, on its own, has little meaning within the mining context as the important factor that needs to be managed is not failure, but risk. In mining, failure with limited adverse consequence is preferable to unnecessary stability at a high cost. Hence a risk-based design approach needs to be applied, where the acceptance criteria is defined in terms of risk and therefore includes probabilistic assessment and risk evaluation components. The risk evaluation process requires some practical understanding of the potential consequences.

Figure 1 illustrates the relationship between Factor of Safety (FS), probability of failure (PF) and risk as design acceptance criteria within the design process. Due to the simplicity and general accepted nature of FS design, the FS assessment is seen as the first step in performing any engineering design. Based on very low values of FS, one may deem the design unacceptable and improve on the design, or in cases where other considerations dictate the design, a very high FS may be sufficient to accept the design. In some circumstances, especially in cases where potential for optimisation exists, the reliability of the design needs to be quantified. Similar to FS, a low or high PF may be sufficient to deem the associated risk inconsequential or unacceptably high.

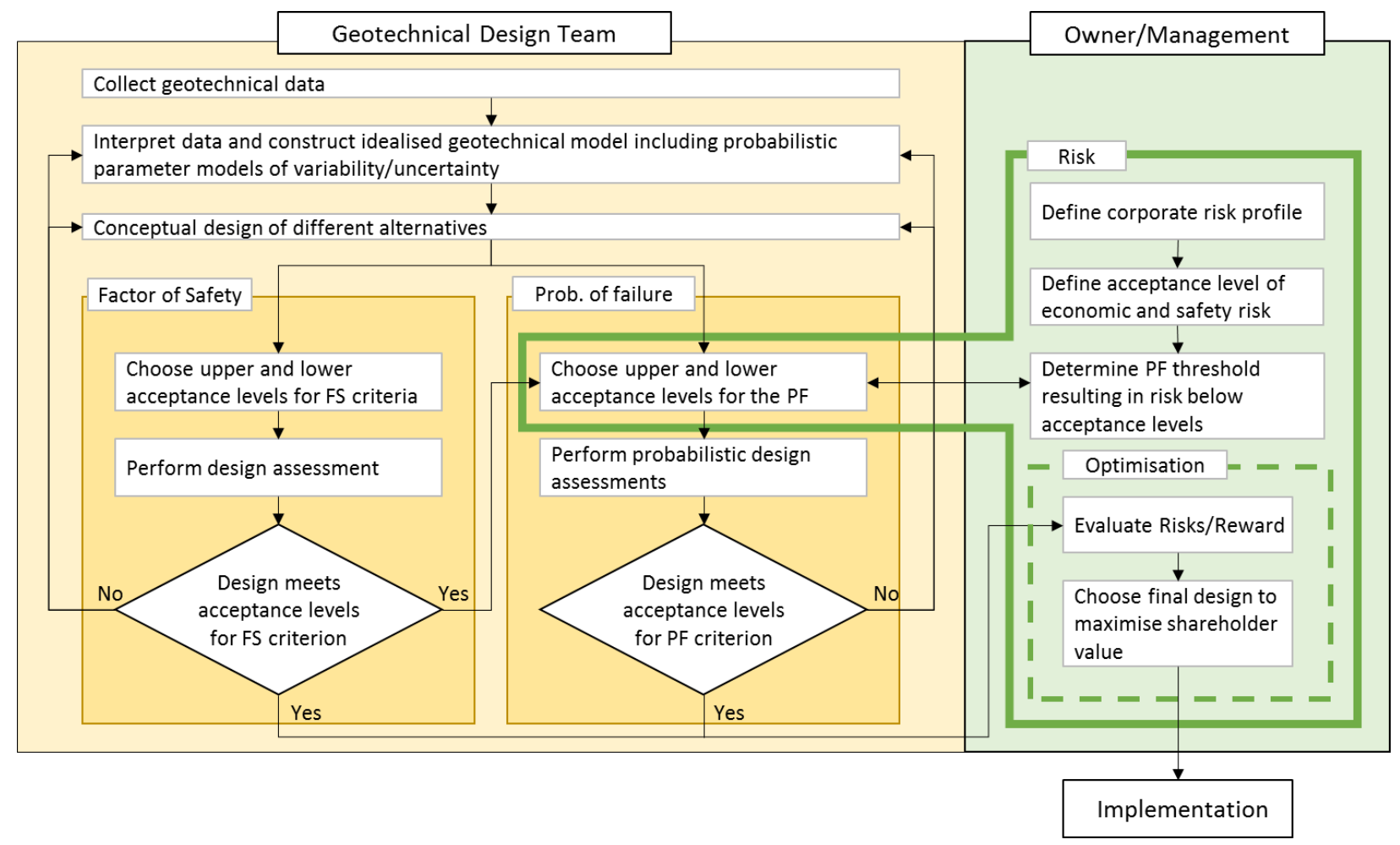

Figure 1 Relationship between FS, PF and risk as design acceptance criterion within the design process (Wesseloo, pers. comm., 2017)

Decision making based on FS or PF is often limited to the geotechnical team. The geotechnical team then implicitly accepts a risk profile without quantification. For some designs in the mine, this may not be acceptable and the risk associated with a design should be quantified. In such cases the design acceptance criteria should be dictated by management through the company risk profile.

The risk assessment provides a context as well as an accepted risk level to which the engineer needs to design. 
Most mining companies utilise risk matrices, such as Figure 2, to define acceptance criteria for risk assessments, which usually involves a great deal of engineering judgement and estimation. The likelihood of an event occurring (rare to certain) and the severity of the consequences (insignificant to catastrophic) form the rows and columns of the matrix and the intersections determine level of risk (low to extreme). While the category names for the levels of likelihood, severity and risk are fairly universal, the boundaries of these categories do vary significantly. The scales are usually qualitative or semi-quantitative and are often updated with time (Brown 2012). Economic risk tolerances may vary depending on the size of the operation. Likelihood categories can be described in terms of probabilities, time periods or simply qualitative descriptions. Applying different likelihood boundaries will influence the interpretation of levels of risk. Some authors have suggested using risk matrices for risk evaluation (Brown 2012; Abdellah et al. 2014; Contreras 2015; Joughin et al. 2016), but the subjective nature of these risk matrices can lead to different interpretations.

\begin{tabular}{|l|c|c|c|c|c|}
\hline \multirow{2}{*}{ Likelihood } & \multicolumn{5}{|c|}{ Severity of consequences } \\
\cline { 2 - 6 } & $\begin{array}{c}\text { Insignificant } \\
>\$ 1,000\end{array}$ & $\begin{array}{c}\text { Minor } \\
>\$ 10,000\end{array}$ & $\begin{array}{c}\text { Moderate } \\
>\$ 100,000\end{array}$ & $\begin{array}{c}\text { Major } \\
>\$ 1,000,000\end{array}$ & $\begin{array}{c}\text { Catastrophic } \\
>\$ 10,000,000\end{array}$ \\
\hline Daily to weekly & High & High & Extreme & Extreme & Extreme \\
\hline$>$ Monthly & Medium & High & High & Extreme & Extreme \\
\hline$>$ Annually & Low & Medium & High & Extreme & Extreme \\
\hline$>1$ in 10 years & Low & Low & Medium & High & Extreme \\
\hline Rare & Low & Low & Medium & Medium & High \\
\hline
\end{tabular}

\section{Figure 2 Risk matrix}

For this paper, the risk matrix in Figure 2 was selected because time intervals are used to define the boundaries of likelihood categories. This enables a more practical interpretation of likelihood, but it is then necessary to convert probabilities into normalised expected frequencies. Weekly, monthly and annual frequencies can then be determined.

An approach to the risk-based geotechnical design under high stress conditions is described in terms of dealing with data uncertainty, probabilistic numerical analysis and risk evaluation. A brief discussion on risk-based design criteria for rockbursts is also included.

\section{$2 \quad$ Evaluating economic risk due to stress damage}

The risk-based design process is described using a conceptual layout for a sublevel of a primary/secondary longhole stoping method (Figure 3 ). The tunnels are typically $5 \times 5 \mathrm{~m}$ cross-sections with an arched roof.

The input data and associated uncertainty is described in Section 2.1, followed by the probabilistic numerical analysis (Section 2.2). A statistical approach is then used to determine the daily frequency and extent of excessive damage (Section 2.3). 


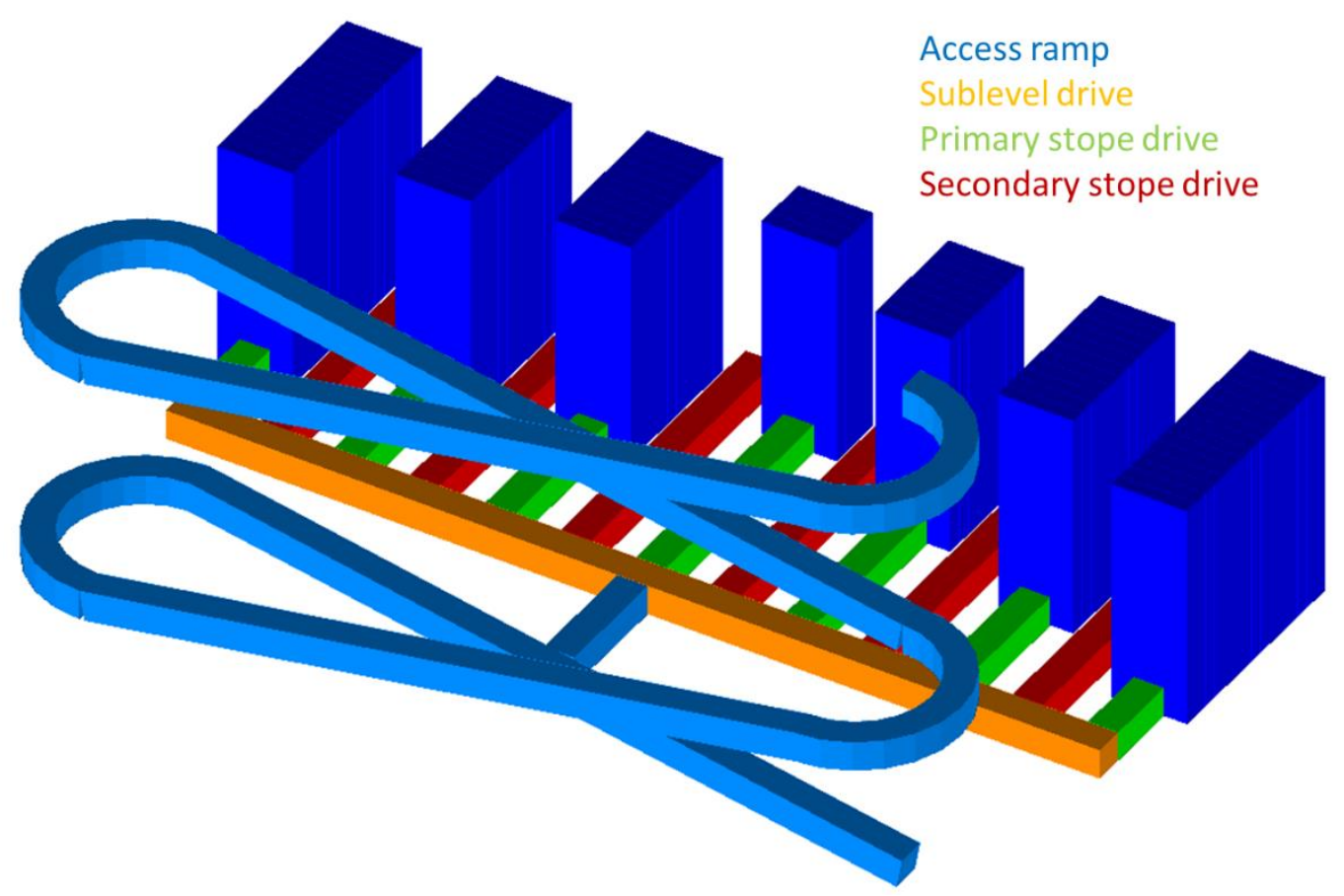

Figure 3 Conceptual mining layout for a primary/secondary longhole stoping sublevel

Excessive stress damage is defined as deformation in excess of the capacity of the support, or the tunnel converges to such an extent that mobile equipment cannot pass and it is then necessary to rehabilitate the tunnel (Figure 4). In section 2.4, cost of damage is evaluated, taking the cost of rehabilitation (removing failed rock and re-supporting the tunnel) and the lost revenue as a result of production interruptions during rehabilitation. The risk is then evaluated by comparing cumulative frequency-loss distributions with the risk (Figure 2).
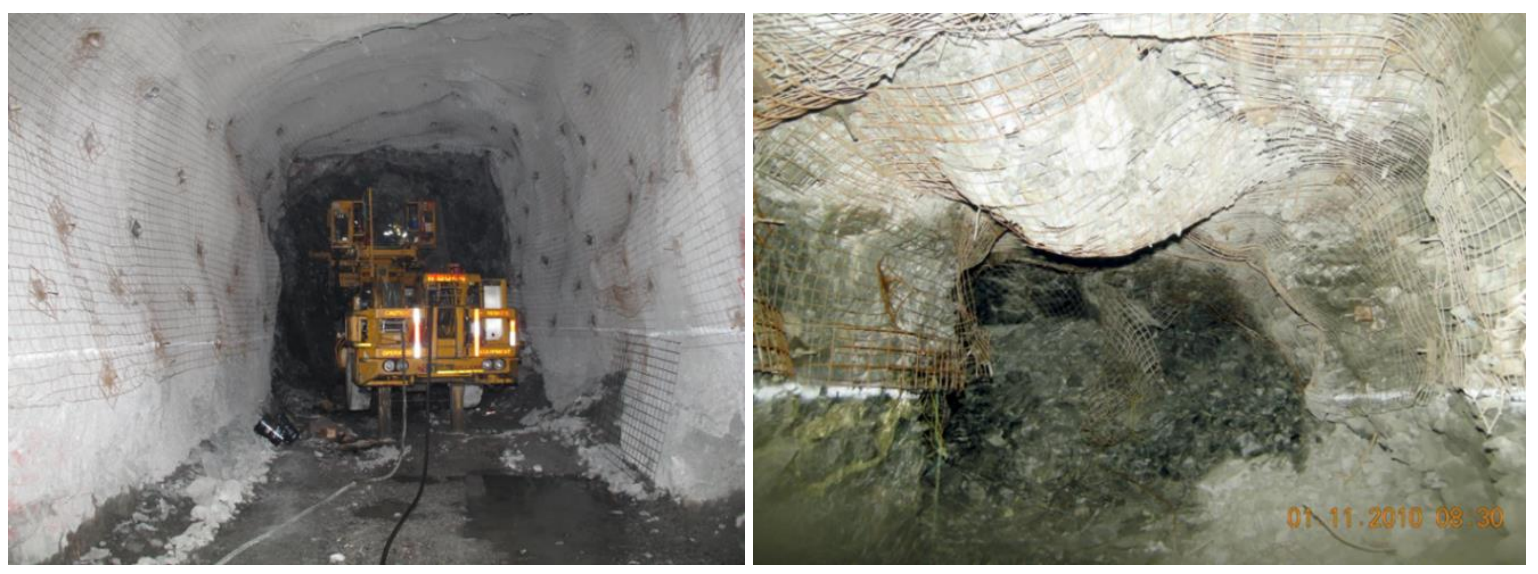

Figure 4 Operational and non-operational stress damaged tunnels (photograph courtesy Brad Simser)

In practice the deformation takes place over time, which enables the safety risk to be managed through convergence and visual monitoring. A method for estimating the risk of injuries was presented by Joughin et al. (2012).

\subsection{Input data}

Rock mass characteristics and intact rock strength properties should be collected for the probabilistic stress analysis (Section 2.2). Increasing the amount and quality of data will improve the confidence in the understanding of the natural variability. It is important to note that this usually increases the variability, as the sample size becomes more representative of the entire population. As a result there is often a tendency to underestimate the natural variability, when there is limited data and it may then be necessary to increase the 
variability using experience and judgement. Confidence intervals of the observed mean (typically 95\%) provide an estimate of the range of the true population mean. The use of confidence intervals to validate the data sets has been discussed by various authors (Baecher \& Christian 2003; Hadjigeorgiou \& Harrison 2011; Contreras \& Ruest 2016). Unconventional methods, such as Bayesian statistics may provide a better way of quantifying uncertainty (Brown 2012; Contreras \& Ruest 2016), but applications are still being developed in geotechnical engineering and tools are not yet readily available. Experience and engineering judgement is essential.

The Hoek-Brown strength criterion was used (Hoek et al. 2002). The Geological Strength Index (GSI) (Marinos \& Hoek 2000; Marinos et al. 2005) can be estimated from geotechnical core logging either directly or by converting from the raw inputs of other rock mass classification systems (Hoek et al. 2013). It is important to composite the GSI data over regular intervals representative of the problem dimension. This is necessary to build a probabilistic model of GSI that captures the variance of the GSI parameter at the scale of the problem. In the case of a $5 \mathrm{~m}$ wide tunnel, the interval length should be between 3 to $10 \mathrm{~m}$ (Figure 5). These interval lengths should be used when estimating the frequency and extent of damage (Section 2.2).

Intact rock strength should be estimated from laboratory tests (uniaxial compressive strength (UCS), triaxial compressive strength (TCS), with at least three different confinements, and Brazilian (BTS) and/or direct tensile tests (DTS). The Hoek-Brown strength envelope for intact rock should be fitted and in this study the $m_{i}$ was assumed to be constant. Assuming a constant $m_{i}$ allows one to calculate the equivalent UCS value for each of the data points and obtain a distribution capturing the variance of the strength envelope.

The rock mass and intact rock strength properties used in this analysis were selected from mining project, which will be developed in a competent igneous rock mass (Figure 6).

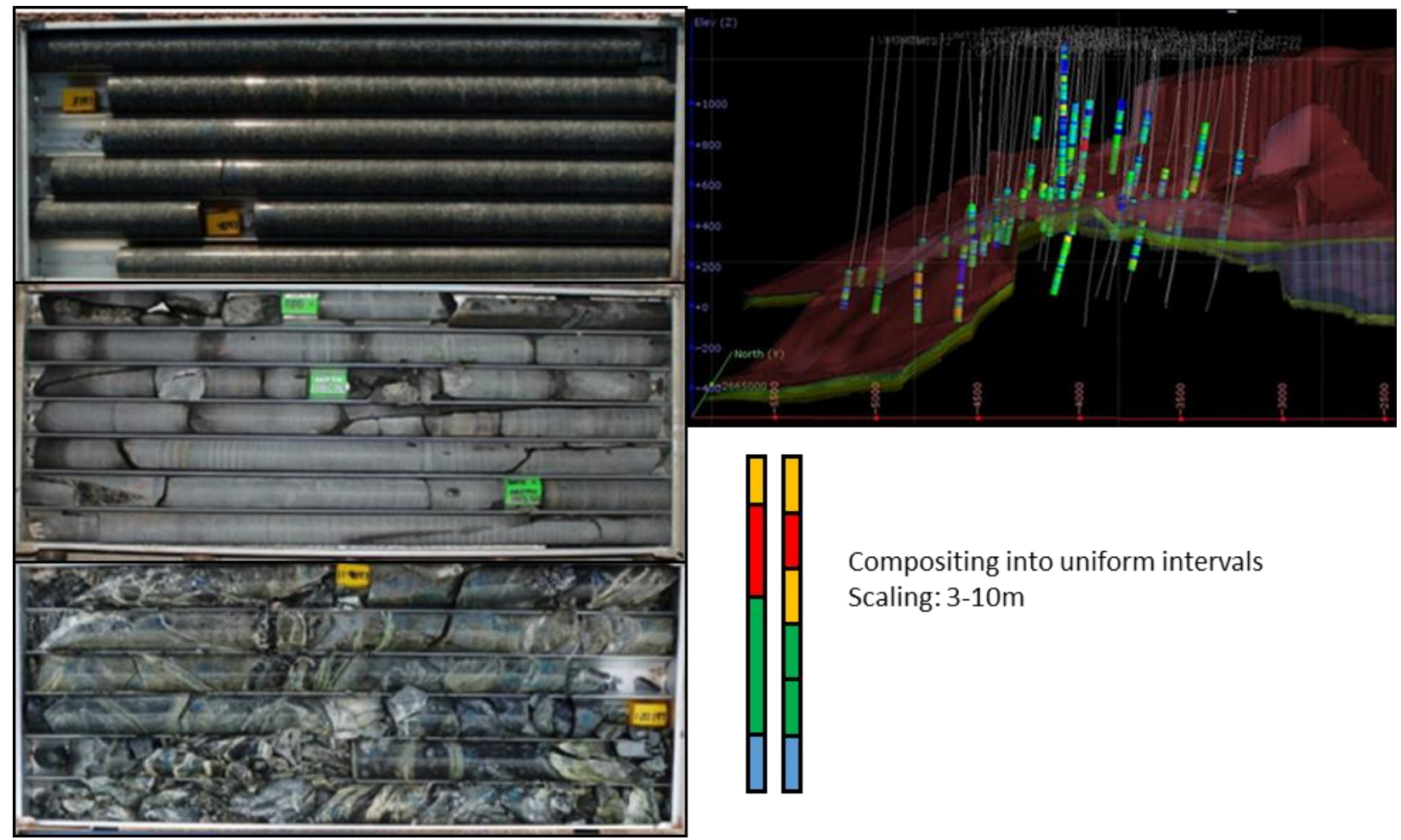

Figure 5 Determining the variability of GSI 


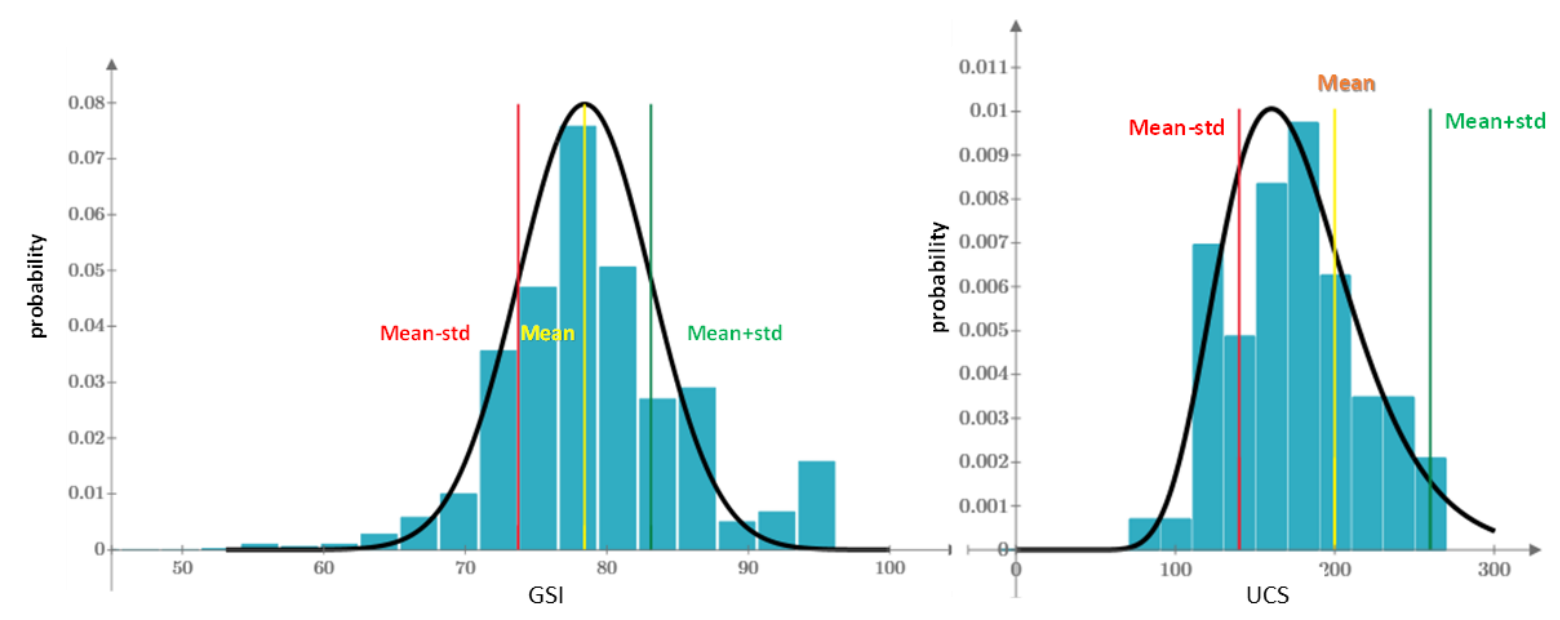

Figure 6 GSI and UCS probability density function

Geometric effects, such as overbreak (as a result of poor blasting) can also be represented in the analyses. Underground measurements of tunnel profiles should be used to determine the overbreak variability. In the absence of actual data, typical values can be used and a triangular distribution can be applied.

Stress uncertainty can have a significant influence on the results of the analyses. Often stress data is limited or not available. Errors are also common in the available stress measurements and it is often not easy to determine whether variability is representative or due to errors. Generally the magnitude of the vertical stress can be estimated with some degree of confidence, but a greater degree of uncertainty is associated with the maximum and minimum horizontal stresses. Principal stress orientations are often not known with certainty. The stress uncertainty for this analysis is represented in Figure 7. Stress measurements, underground observations and local knowledge should be used to guide the shape of the distribution.
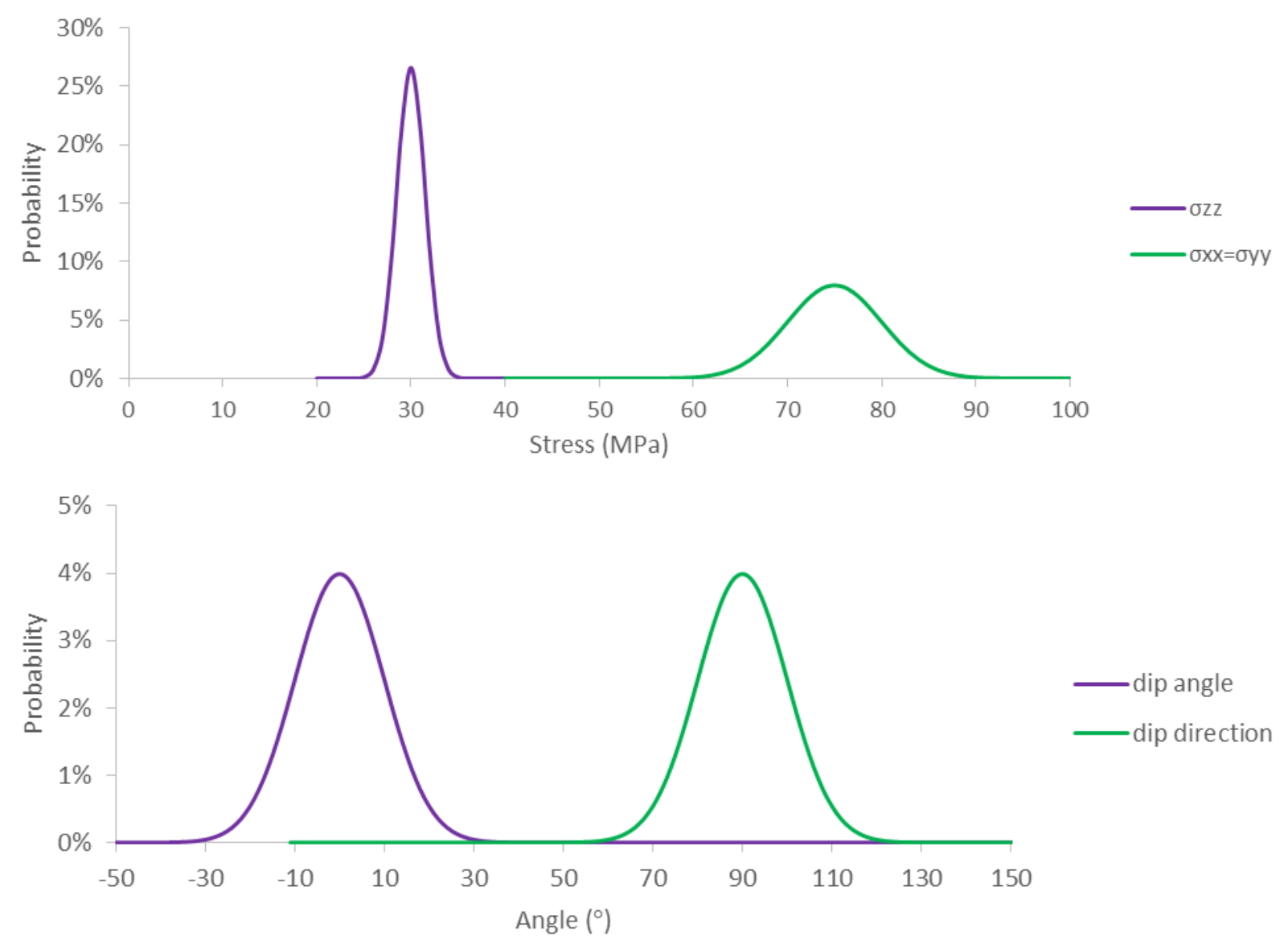

Figure 7 Probability distributions of stress uncertainty 
If any of the input variables are correlated, then the correlation coefficients should be determined. GSI and UCS are usually not correlated, but it is important to test. The overbreak variable is meant to be related to poor blasting, but the GSI or rock strength could possibly influence the extent of overbreak. Some probabilistic methods are not applicable when there is a correlation between input parameters and in others, such as the Point Estimate Method (Section 2.2), this needs to be taken into account. It is usually better to design the probabilistic stress analysis with input variables that are not correlated.

\subsection{Probabilistic stress analysis}

In probabilistic analyses, the Monte-Carlo (MC) approach (Kroese \& Rubinstein 2012) is the best known and most widely used. However, numerical modelling, particularly elasto-plastic methods, require long solution times and it is generally not practical to run many models and therefore alternate methods are more typically used. Three methods, namely the Point Estimate Method (PEM) (Rosenblueth 1975; Rosenblueth 1981; Harr 1996; Christian \& Baecher 1999; Valley et al. 2010; Christian \& Baecher 2002), response surface method (RSM) (Bradley 2007; Langford \& Diederichs 2015; Lü \& Low 2011b), and the response influence factor (RIF) (Tapia et al. 2007; Wesseloo \& Read 2009; Chiwaye \& Stacey 2010; Steffen et al. 2008; Joughin et al. 2016) are more often used to perform probabilistic analysis computational efficiency is critical.

An efficient probabilistic analysis approach, which utilises elastic modelling and the principle of superposition of load effects has been developed in an mXrap (Harris \& Wesseloo 2015) app (Wesseloo 2016). It is considered that the loads and their resulting effects can be added or subtracted providing that the structure behaves as a linear elastic material. Unit stress analyses are conducted for each component of the stress tensor. The analysis for this example was performed in Map3D Fault Slip (Wiles 2016). The results are imported into the $m X$ rap app and the resultant induced stress for any given field stress can be calculated using the method of elastic stress superposition (Wesseloo 2016). This novel approach enables complex mine geometries to be modelled and a rigorous MC Simulation to be performed with minimal computer time.

Figure 8 shows the model geometry used to determine the stress acting on a primary stope drive during the extraction of primary stopes. The MC analysis was carried out using the results of the unit stress elastic models with frequency distributions of UCS, GSI, stress magnitudes and orientations (Section 2.1). The Hoek-Brown strength factor was used to determine the depth of failure in each iteration of the MC solution.

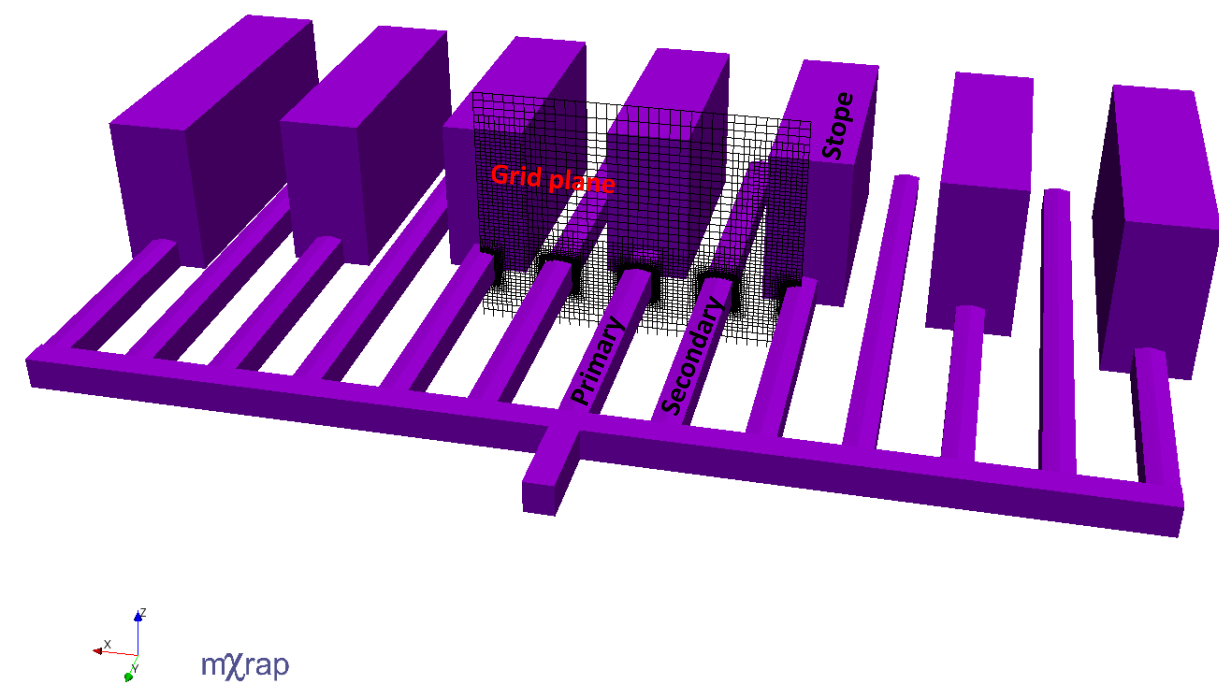

Figure 8 Isometric view of the model geometry

The results of the probabilistic stress analysis for primary stope drives is presented in Figure 9 in terms of probability of stress damage. The central primary stope drive is the one of interest for the analysis. At this stage in the model, the secondary stopes experience less damage and the outer primary stope drives experience more damage, but the stress grid is adjacent to the stope indicating brow effects. These results can be used to determine the probability of a given depth of failure. 


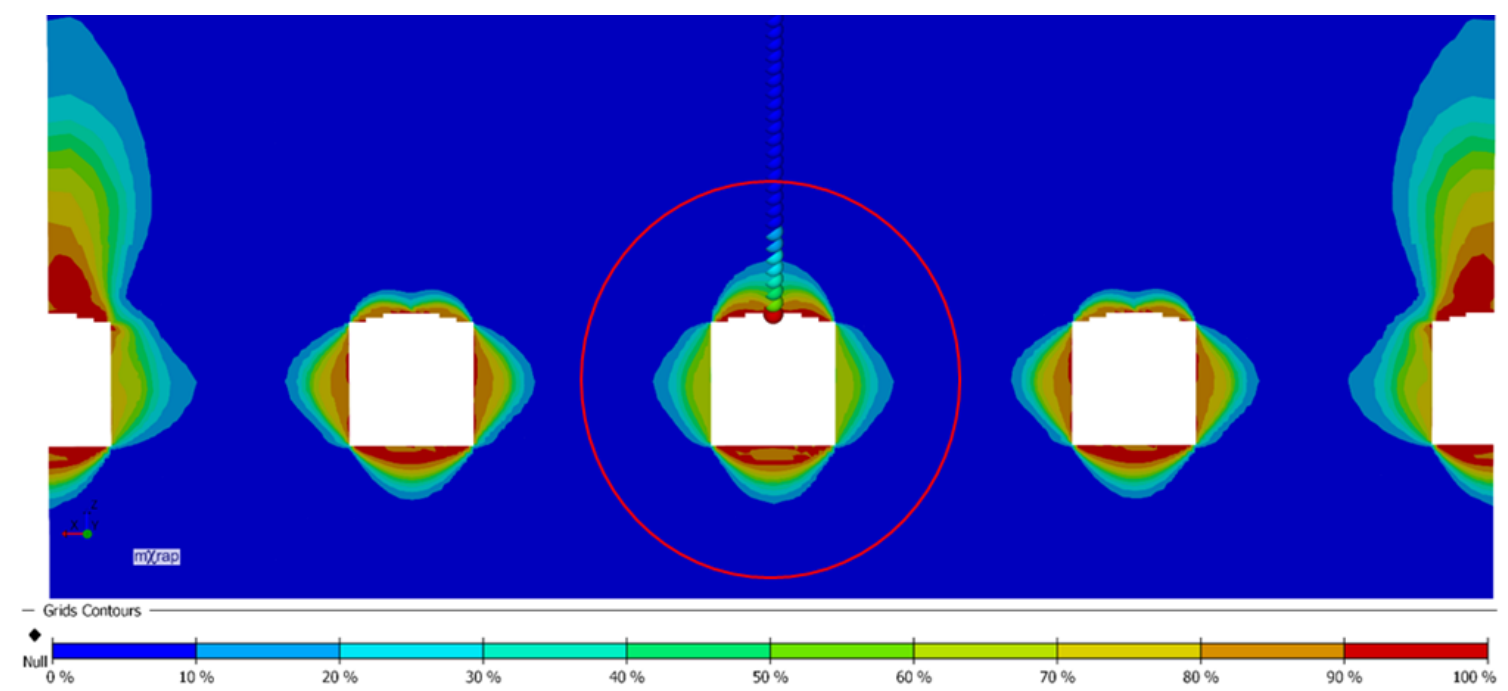

Figure 9 Probability of stress damage around a stope drive

The anticipated deformation can be estimated by multiplying the depth of failure by the appropriate bulking factor in Table 1 (Kaiser et al. 1995). Cumulative probability distributions of deformation for stope drives and the access ramp, determined using this method, are presented in Figure 10. The letters $A, B$, and C represent the support systems described in Table 1 , where $A$ has the lowest load capacity and $C$ has the highest load capacity.
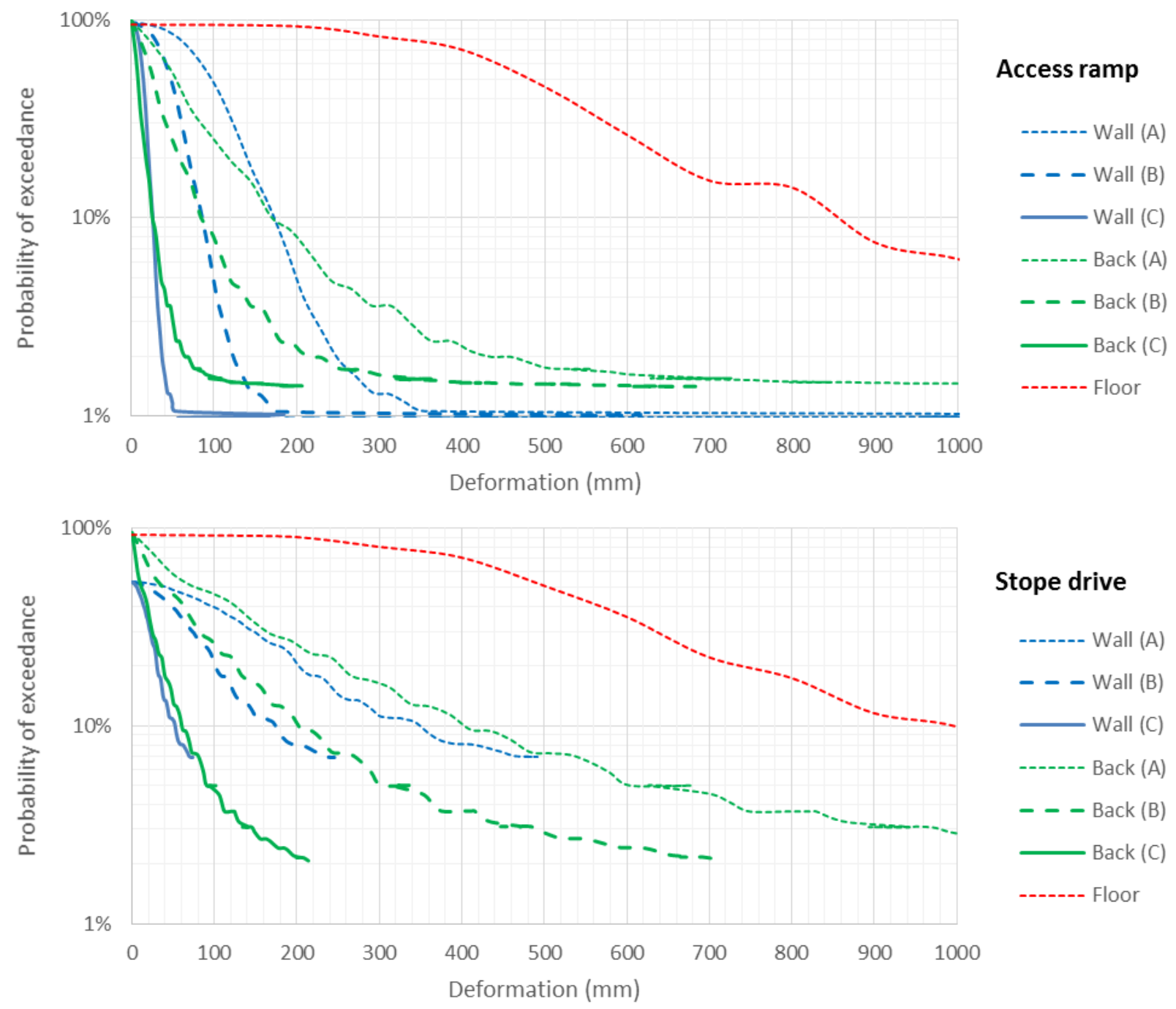

Figure 10 Cumulative probability distributions of deformation (stope drive and access drive) 
Table 1 Rock mass bulking factors (BF) (Kaiser et al. 1995)

\begin{tabular}{|c|c|c|c|}
\hline Location and support condition & $\begin{array}{l}\text { Average support } \\
\text { load capacity } \\
\left(\mathrm{kN} / \mathrm{m}^{2}\right)\end{array}$ & $\begin{array}{l}\text { Recommended } \\
\text { bulking factor } \\
\text { (BF) }\end{array}$ & $\begin{array}{l}\text { Severity of } \\
\text { anticipated } \\
\text { damage }\end{array}$ \\
\hline Floor heave & 0 & $\begin{array}{l}30 \pm 5 \% \\
>50 \%\end{array}$ & $\begin{array}{l}\text { Minor to moderate } \\
\text { Major }\end{array}$ \\
\hline $\begin{array}{l}\text { Walls and backs } \\
\text { Light standard bolting and loose, light mesh }\end{array}$ & $<50$ & $10 \pm 3 \%$ & Minor to moderate \\
\hline Yielding support & $<200$ & $5 \pm 1 \%$ & Minor to major \\
\hline $\begin{array}{l}\text { Strong support with rock mass } \\
\text { reinforcement }\end{array}$ & $>200$ & $1.5 \pm 0.5 \%$ & Minor to major \\
\hline
\end{tabular}

The access ramp being situated further from the active stoping has more favourable cumulative probability distributions of deformation, which is expected. The support system needs to be designed (length, strength, and ductility of bolts and containment support) to cater for a specified deformation using experience and engineering judgement. Alternatively, the design engineer may choose to modify the mining layout or sequence to improve the probability distributions of failure. Mitigating the risk is likely to increase the operating costs and, therefore, an economic risk analysis is required. Note that the uncertainty and corresponding probability of exceeding the specified deformation may also be reduced by spending money on more detailed investigations.

The acceptable probabilities for the two types of excavations will not be the same, because the economic losses associated with production disruptions are much greater in the case of access ramps. To determine appropriate 'probabilities of failure' it is necessary to estimate the expected frequency and extent of severe damage (Section 2.3) and evaluate the risk (Section 2.4).

\subsection{Estimation of the frequency and extent of excessive deformation}

It is necessary to determine the daily frequency of occurrence of damage affecting a given length of tunnel, hence a model must be developed.

The total length $(L)$ of the access ramp, sublevel drive or stope drives will not normally be affected at the same time. In practice, the potentially affected length $\left(I_{p}\right)$ at a given time will be a function of the mining layout and sequence and the resulting stress influence (Figure 11). In the case of stope drives, the greatest stress change is experienced close to the stope abutment and this is when large deformations are most likely to occur. The probabilistic stress analysis (Section 2.2) can be used as a guide to determining $I_{p}$. For the sublevel drives, the greatest stress change will occur as a stope reaches its limit. The access drive will experience less significant stress changes, since it is further away and while the probability of exceeding deformation criteria is expected to be lower, the potentially affected length may be larger. Selecting an appropriate $I_{p}$ will always be subjective, particularly in the case of the access ramp, and it is therefore necessary to test different $l_{p}$ values and assess the influence on the model.

This $I_{p}$ can be further sub-divided into short tunnel segment lengths $\left(I_{s}\right)$, which represent the natural variability in rock mass characteristics and ideally references to the composite interval length used for determining the variability of the GSI (Section 2.1).

The probability $(p)$ of exceeding the deformation criteria, determined using the method described in Section 2.2, is therefore applicable to the segment length. When the $I_{p}$ is affected, some or all of the length may experience excessive deformation. Figure 12 shows some scenarios of possible damage over $l_{p}$ for a given $p$. 

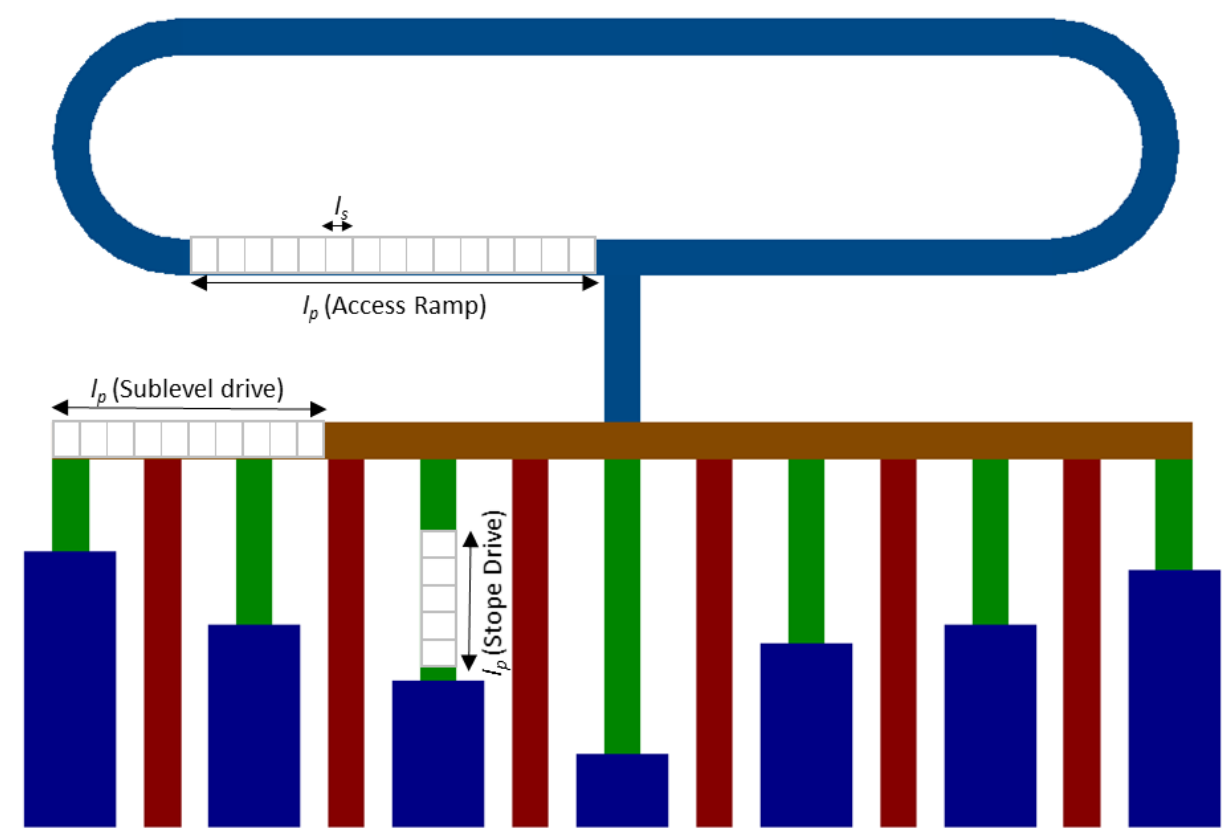

Figure 11 Potential damage zones

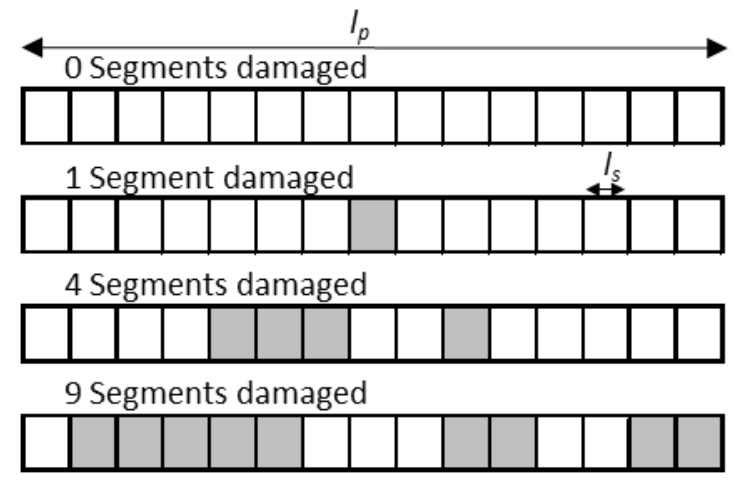

Figure 12 Possible damage over the potentially affected length of a tunnel

The probability $\operatorname{Pr}(k, p, n)$ of exactly $k$ segments being excessively damaged can be estimated using the binominal distribution:

$$
\operatorname{Pr}(\mathrm{k}, \mathrm{p}, \mathrm{n})=\frac{n !}{k !(n-k) !} p^{k}(1-p)^{n-k}
$$

Where $n$ is the total number tunnel segments and is calculated as nearest rounded up integer as follows:

$$
n=l_{p} / l_{s}
$$

The cumulative form of the distribution, representing the probability $\operatorname{Pr}(\geq k)$ of more than $k$ tunnel segments being damaged is:

$$
\operatorname{Pr}(\geq \mathrm{k}, \mathrm{p}, \mathrm{n})=\sum_{i=k}^{n} \frac{n !}{i !(n-i) !} p^{i}(1-p)^{n-i}
$$

The binomial distribution is a standard function in excel, but it should be noted that the cumulative form of the binomial distribution in excel calculates $\operatorname{Pr}(\leq k, p, n)$, but it is easy to calculate $\operatorname{Pr}(\geq k, p, n)$. The length of damage, $l_{d}$, for a given $k$ and $I_{s}$ is:

$$
l_{d}\left(k, l_{s}\right)=l_{s} k
$$

Figure 13 shows cumulative probability damaged tunnel length distributions, for the total tunnel length under consideration $I_{p}=45 \mathrm{~m}$ and a range of $p$ values determined using the binomial distribution. 


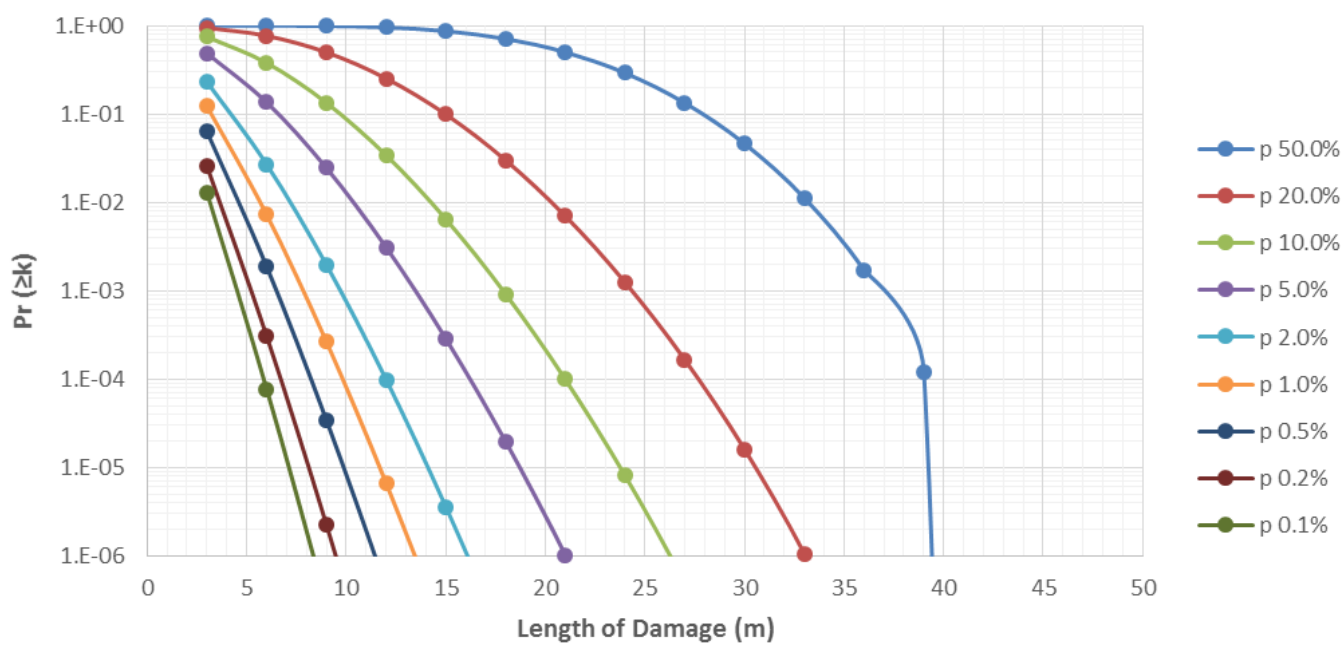

Figure 13 Cumulative probability damage length distributions for $I_{p}=45 \mathrm{~m}$ and values of $p$ from 0.1 to $50 \%$

During the life of the sublevel being mined, the entire $L$ of access ramp, sublevel drive and stope drives will be affected at some time. The number of potentially affected lengths $(N)$ is:

$$
N=L / l_{p}
$$

The expected frequency $F(\geq k, p, n, N)$ of occurrence of $I_{d}(k)$ can then be estimated as follows:

$$
F(\geq k, p, n, N)=\operatorname{Pr}(\geq k, p, n) N
$$

The $F(\geq k, p, n, N)$ should be normalised over the duration of mining $(T)$ as follows:

$$
F_{T}(\geq k, p, n, N, T)=\frac{\operatorname{Pr}(\geq k, p, n) N}{T}
$$

The time unit for normalisation could be days, weeks, months, quarters or years. The likelihood intervals in the risk matrix (Figure 2) for different normalised expected frequencies are presented in Table 2. In this example, the expected frequency was normalised by years.

Table 2 Normalising the expected frequency

\begin{tabular}{llllll}
\hline Likelihood & \multicolumn{7}{l}{ Normalised expected frequency } \\
\hline & Years & Quarters & Months & Weeks & Days \\
\hline Daily & 365 & 92 & 30.5 & 7.0 & 1.0 \\
Weekly & 52 & 13 & 4.4 & 1.0 & 0.1 \\
Monthly & 12 & 3 & 1 & 0.23 & 0.0 \\
Annual & 1 & 0.25 & 0.083 & 0.019 & 0.0027 \\
\hline $1 / 10$ years & 0.1 & 0.025 & 0.0083 & 0.0019 & 0.00027 \\
\hline $1 / 100$ years & 0.01 & 0.0025 & 0.00083 & 0.00019 & 0.000027 \\
\hline
\end{tabular}

In this example the following general parameters were used:
Duration
$(T)=3$ years.
Segment length
$\left(I_{s}\right)=3 \mathrm{~m}$
Probability of exceeding deformation criteria
(p): 0.1 to $50 \%$.

The input parameters specific to the access ramp, sublevel drive and stope drives are listed in Table 3 . Note that for the access ramp, only the total length that services the sublevel was considered. 
Table 3 Specific input parameters for the frequency and extent of damage analysis

\begin{tabular}{llll}
\hline Parameter & Access ramp & Sublevel drive & Stope drives \\
\hline Total length $(L)$ & $500 \mathrm{~m}$ & $225 \mathrm{~m}$ & $900 \mathrm{~m}$ \\
Potential affected length $\left(I_{p}\right)$ & $42 \mathrm{~m}$ & $30 \mathrm{~m}$ & $15 \mathrm{~m}$ \\
\hline Number of potentially affected lengths $(N)$ & 12 & 8 & 60 \\
Number of segments $(n)$ & 14 & 10 & 5 \\
\hline
\end{tabular}

The cumulative normalised expected frequency damage length distributions are presented in Figure 14. The likelihood intervals are shown on the right hand axis for reference purposes. Note that the $F_{T}$ values are highest for the stope drives because they have the greatest $N$. However, the maximum length of damage $I_{d}\left(n, I_{s}\right)$ is limited by $I_{p}$. While the access ramp has greatest $I_{d}\left(n, I_{s}\right)$ values, it is expected that $p$ will be relatively low, because it is further away from the stopes. In fact, it is essential to ensure that $p$ is low, because the access ramp affects all of the potential production from the sublevel. This frequency damage model is used to evaluate the economic risk in Section 2.4.
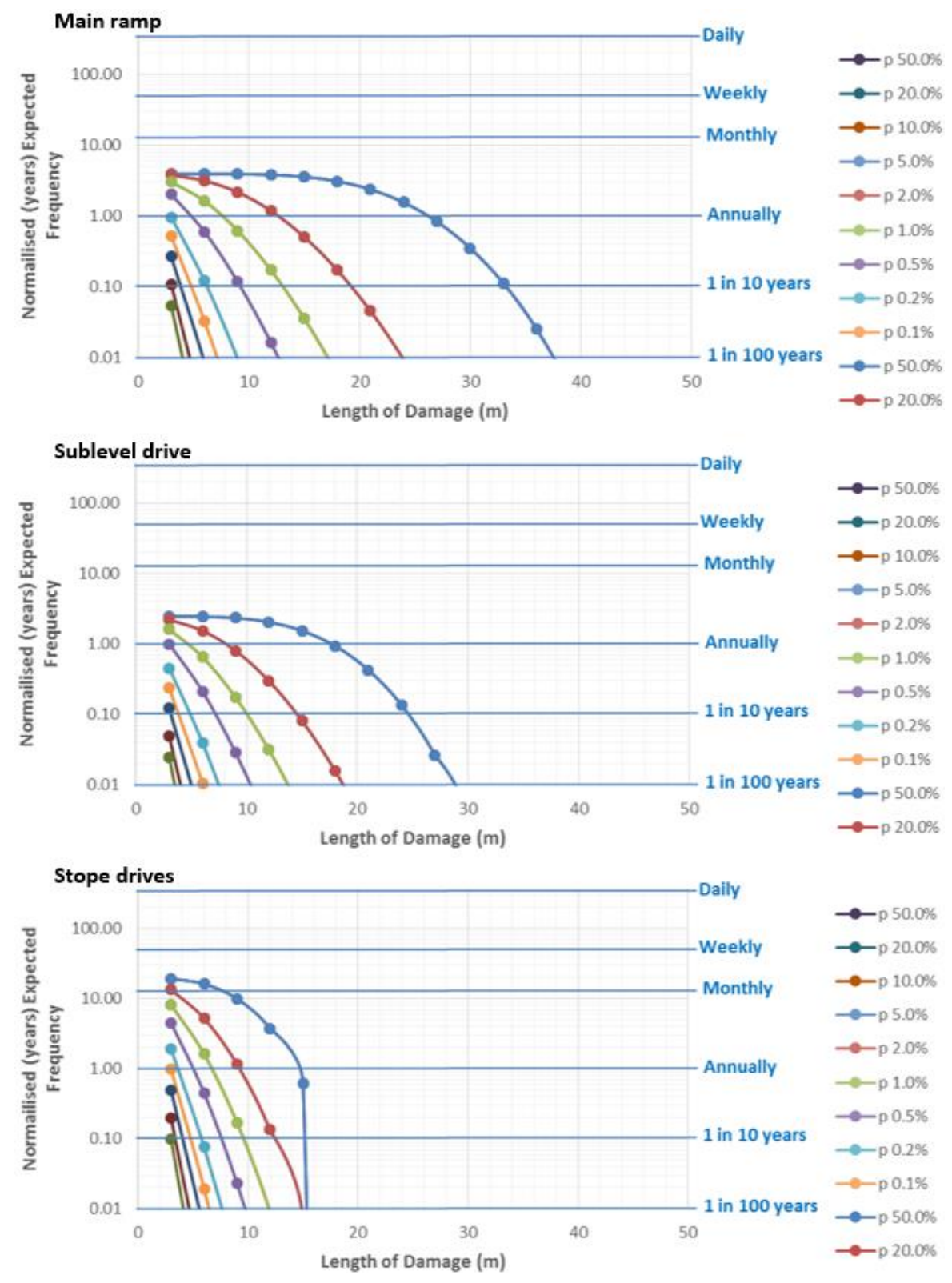

Figure 14 Cumulative normalised (years) expected frequency damage length distributions 


\subsection{Economic risk evaluation}

The estimation of losses associated with rock damage in underground mines has been addressed by a few authors (Joughin et al. 2012; Abdellah et al. 2014; Joughin et al. 2016). The most significant economic consequences of the damage are the cost of remediation of the damaged section of the tunnel and the lost production due to inaccessibility during rehabilitation.

Rehabilitation usually involves the removal of loose rock and damaged support and then re-supporting. It is best to obtain estimates of the cost $\left(c_{r}\right)$ and rate $(r)$ of rehabilitation using data from previous tunnel repairs. The cost of rehabilitation $C_{r}\left(k, I_{s}\right)$ and duration $t_{r}\left(k, I_{s}, r\right)$ of rehabilitation can be estimated using the $I_{d}\left(k, l_{s}\right)$ (Section 2.3) as follows:

$$
\begin{aligned}
C_{r}\left(k, l_{s}, c_{r}\right) & =l_{d}\left(k, l_{s}\right) c_{r} \\
t_{r}\left(k, l_{s}, r\right) & =l_{d}\left(k, l_{s}\right) r
\end{aligned}
$$

The following input values were used in this example:

- Cost of rehabilitation: $c_{r}=\$ 2,000 / \mathrm{m}$.

- Rate of rehabilitation: $r=1 \mathrm{~m} /$ day.

During rehabilitation, production is likely to be affected, but this depends on the purpose of the tunnel. Referring to Figure 11, rehabilitation in the main access ramp would always affect the full production from these stopes and this will have an immediate effect. Rehabilitation of the sublevel drive would probably only effect half of the production and there may be some flexibility $\left(t_{f}\right)$ in the production schedule that allows one or two days before production is affected. The proportion of daily production influenced when a stope drive is being rehabilitated depends on the number of active stopes in production and there is invariably some flexibility, so the production impact is not immediate. The lost production time can be estimated as follows:

$$
t_{p}\left(k, l_{s}, r, t_{f}\right)=t_{r}\left(r, k, l_{s}\right)-t_{f}
$$

The following model can be used to estimate the potential loss per damaging incident as a function of length of damage:

$$
C_{p}\left(k, l_{s}, r, t_{f}, c_{p}, a, m, b\right)=t_{p}\left(k, l_{s}, r, t_{f}\right) \cdot c_{p} \cdot(1-a) \cdot m \cdot b
$$

where:

$c_{p}$ is the revenue per ton mined.

$a$ is the direct cost of production as a proportion of revenue.

$m$ is the daily production from the sublevel.

$b$ is the proportion of daily production affected.

The total potential loss per damaging incident is then:

$$
C_{T}\left(k, l_{s}, c_{r}, r, t_{f}, c_{p}, a, m, b\right)=C_{r}\left(k, l_{s}, c_{r}\right)+C_{p}\left(k, l_{s}, r, t_{f}, c_{p}, a, m, b\right)
$$

The model parameters should be based on the production layout and schedule and economics. The following general input parameters were used in this example:

- Revenue per ton mined: $\quad C_{p}=\$ 155 / \mathrm{t}$.

- Direct cost of production: $\quad a=20 \%$.

- Daily production:

$m=1000 \mathrm{t}$.

The specific model input parameters for the different types of excavations are listed in Table 4. 
Table 4 Specific economic model input data for the different types of excavations

\begin{tabular}{llll}
\hline Parameter & Access ramp & Sublevel drive & Stope drives \\
\hline Proportion of daily production affected & $100 \%$ & $50 \%$ & $25 \%$ \\
Flexibility or time until impact $\left(t_{f}\right)$ & 0 days & 2 days & 5 days \\
\hline
\end{tabular}

Using the cumulative normalised expected frequency damage length distributions of Section 2.3 and the economic model, cumulative normalised expected frequency distributions of economic loss can be presented using the risk matrix in Figure 2. Risk profiles have been determined for the access ramp (Figure 15), sublevel drive (Figure 16) and stope drives (Figure 17).

Note that severity is greatest for the access ramp, due to the amount of production effected and the immediate loss of production. The cost of rehabilitation ranges from insignificant to minor, while production losses range from moderate to major depending on the number of days lost. The frequency of excessively damaging events is greatest for the stope drives due to the total length of the stope drives, but the losses are much lower (typically minor) due to greater flexibility and lower production impact.

Increasing the $I_{p}$ reduces the frequency of minor events and increases the maximum severity of an event. It is possible to dynamically change the input parameters and check the influence on the risk profile.

The $p$ value for design should be selected to ensure that the risk is medium and the expected loss is low relative to daily revenue. Based on the risk profiles presented, the $p$ values for design should be $2 \%$ for access drives, $5 \%$ for sublevel drives and $10 \%$ for stope drives.

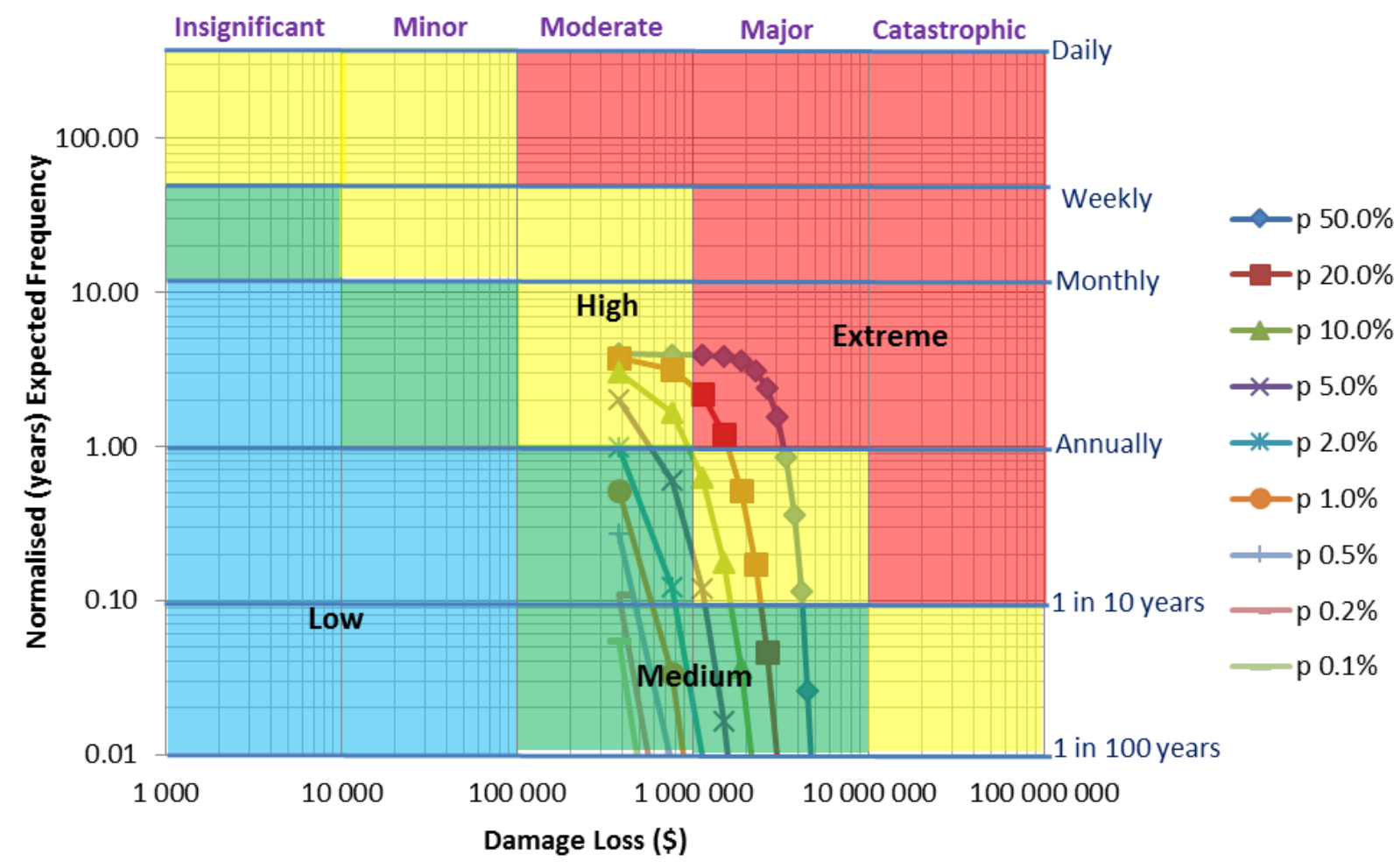

Figure 15 Risk profile for the access ramp 


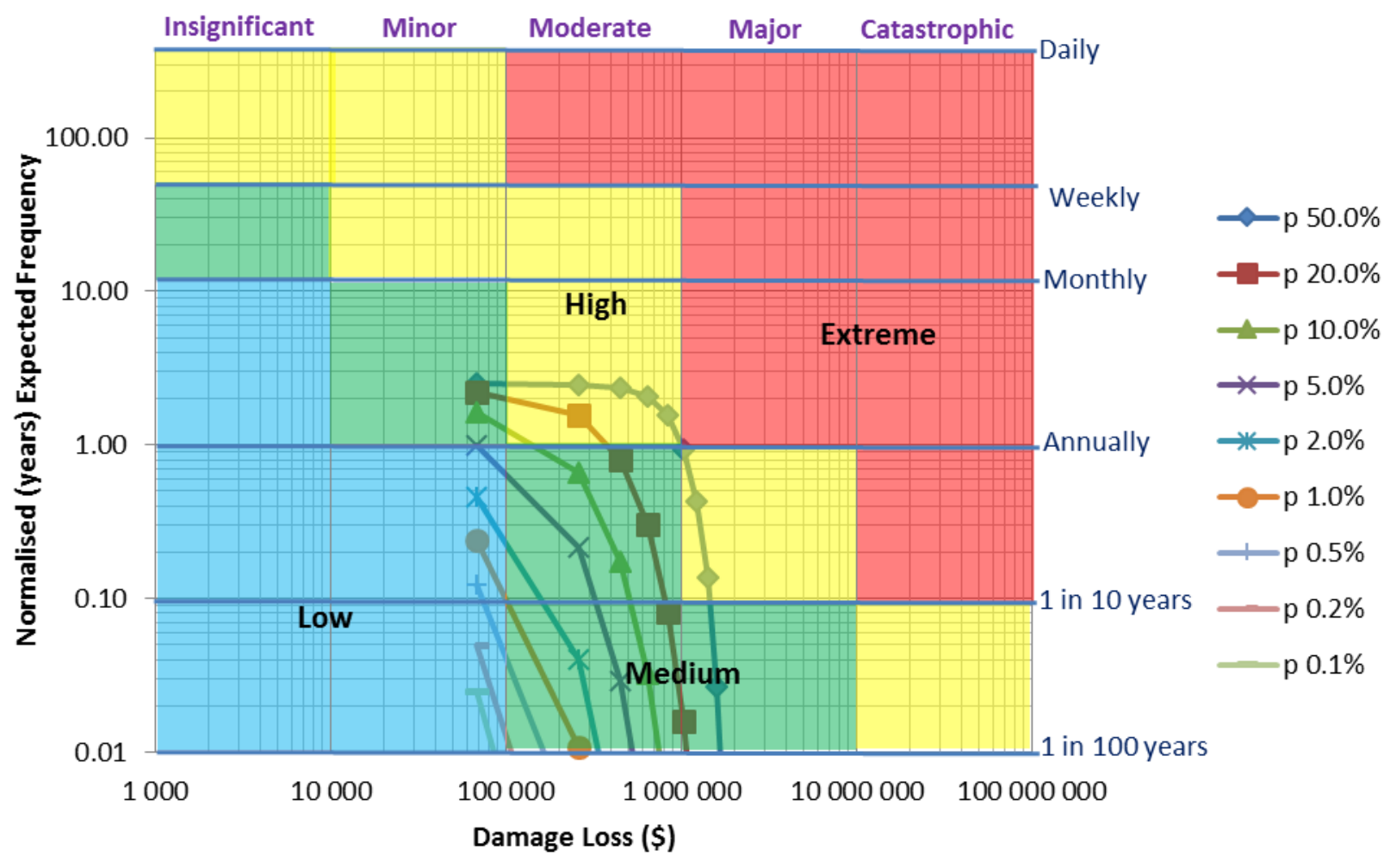

Figure 16 Risk profile for the sublevel drive

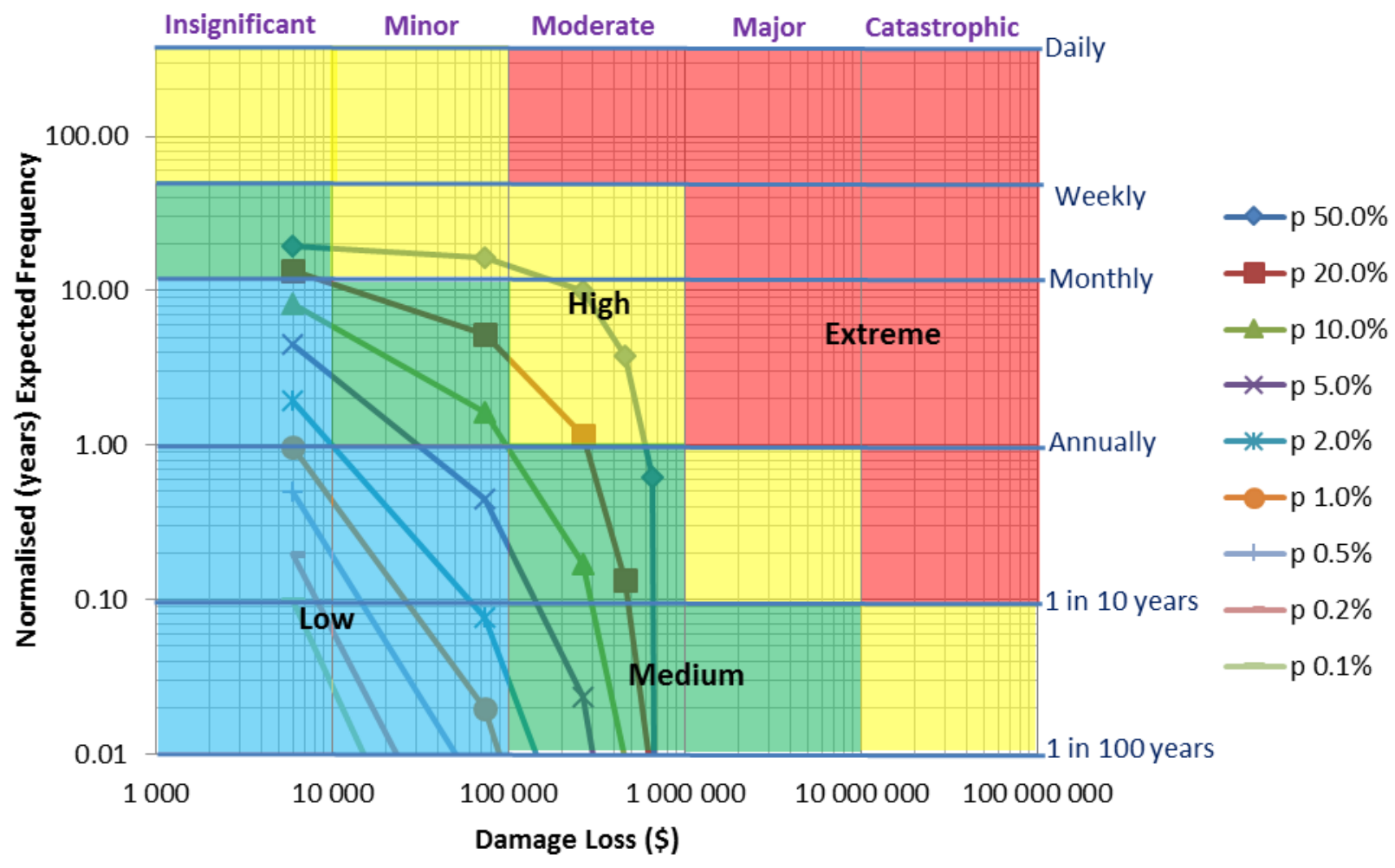

Figure 17 Risk profile for stope drives

\section{Seismic risk criteria for support design}

When designing support to mitigate seismic risk, the concept of energy absorption is commonly used. The energy demand is the sum of the kinetic and potential energy of a potential rock ejected during a seismic event (Ryder \& Jager 2002; Kaiser et al. 1995). It is necessary to estimate the expected peak ground velocity 
(PGV) to determine the kinetic energy demand. This can be determined by statistically analysing recorded seismic events and using an empirical ground motion relation to estimate the PGV on mine access tunnels (Wesseloo 2013). However, this does not represent the PGV associated with future seismicity as a result of ongoing mining.

A novel method of modelling seismicity has been developed and incorporated in the boundary element software ISSM (Malovichko \& Basson 2014). Fictitious Force elements are used to model the existing mining layout and planned mining sequence. Displacement discontinuity elements are used to simulate flaws applying the Salamon-Linkov method (Salamon 1993; Linkov 2005). Malovichko and Basson correlated recorded and modelled seismicity at Renison mine (Figure 18) and found that there was a reasonable spatial correlation (in the area of interest) and size correlation for the larger events, which enables the results to be used with some caution.

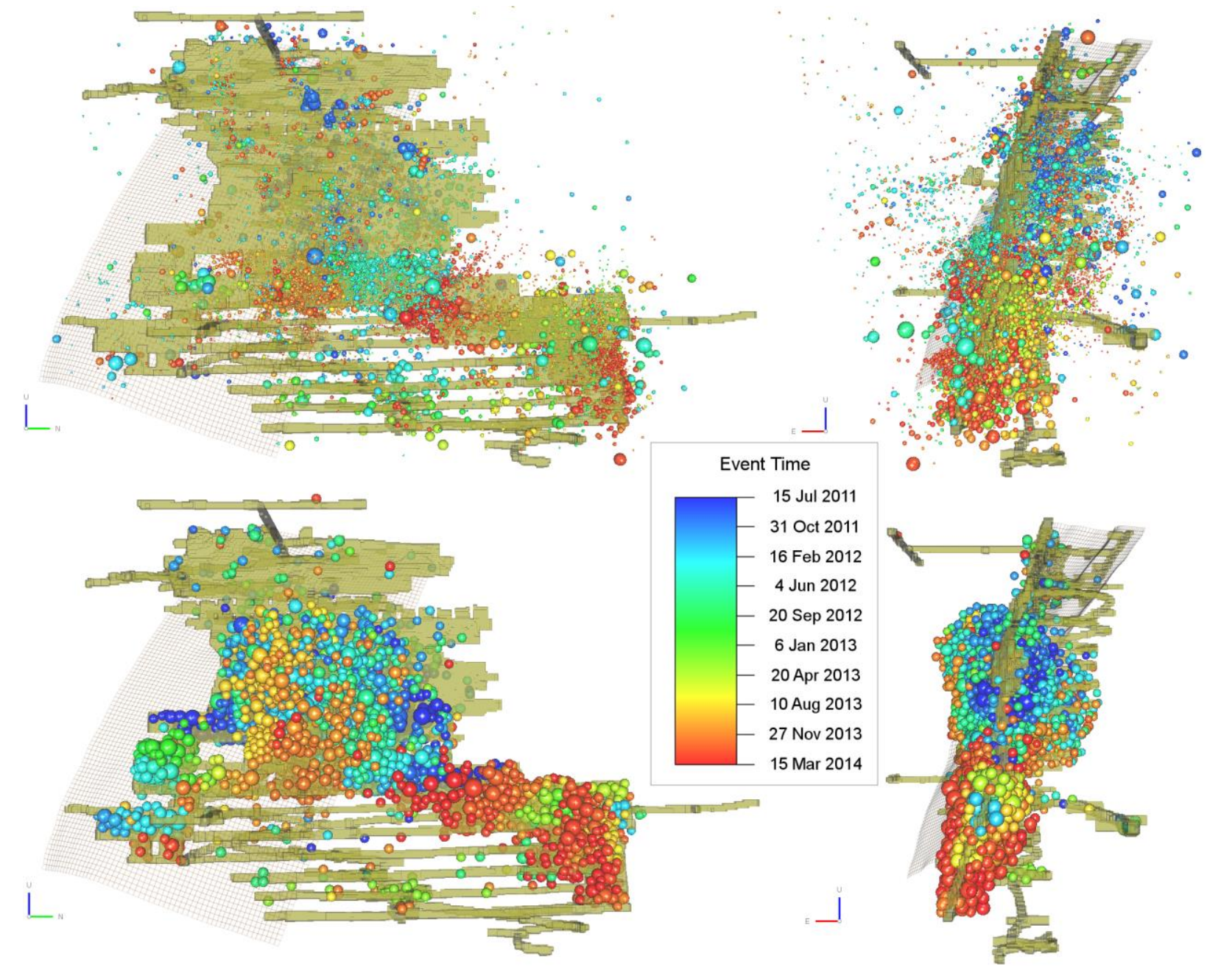

Figure 18 Recorded seismicity (top) and modelled seismicity (bottom) for Renison mine after Malovichko and Basson (2014)

The seismic hazard can be assessed using both recorded and modelled seismicity (Malovichko 2017). The results are then converted to ground motion hazard by applying a ground motion prediction equation (GMPE) and a MC simulation taking the variability of the GMPE equation into consideration. Isosurfaces of PGV can be generated for different probabilities of exceedance.

Renison management selected once in ten years as an acceptable likelihood of occurrence (Figure 2). This is equivalent to a 0.025 probability of occurrence within one quarter (92 days) (Table 2). Figure 19 shows isosurfaces of PGV $(\mathrm{m} / \mathrm{s})$ for which the probability of exceedance is once in ten years.

This approach is used to determine the dynamic support requirements on the mine. 


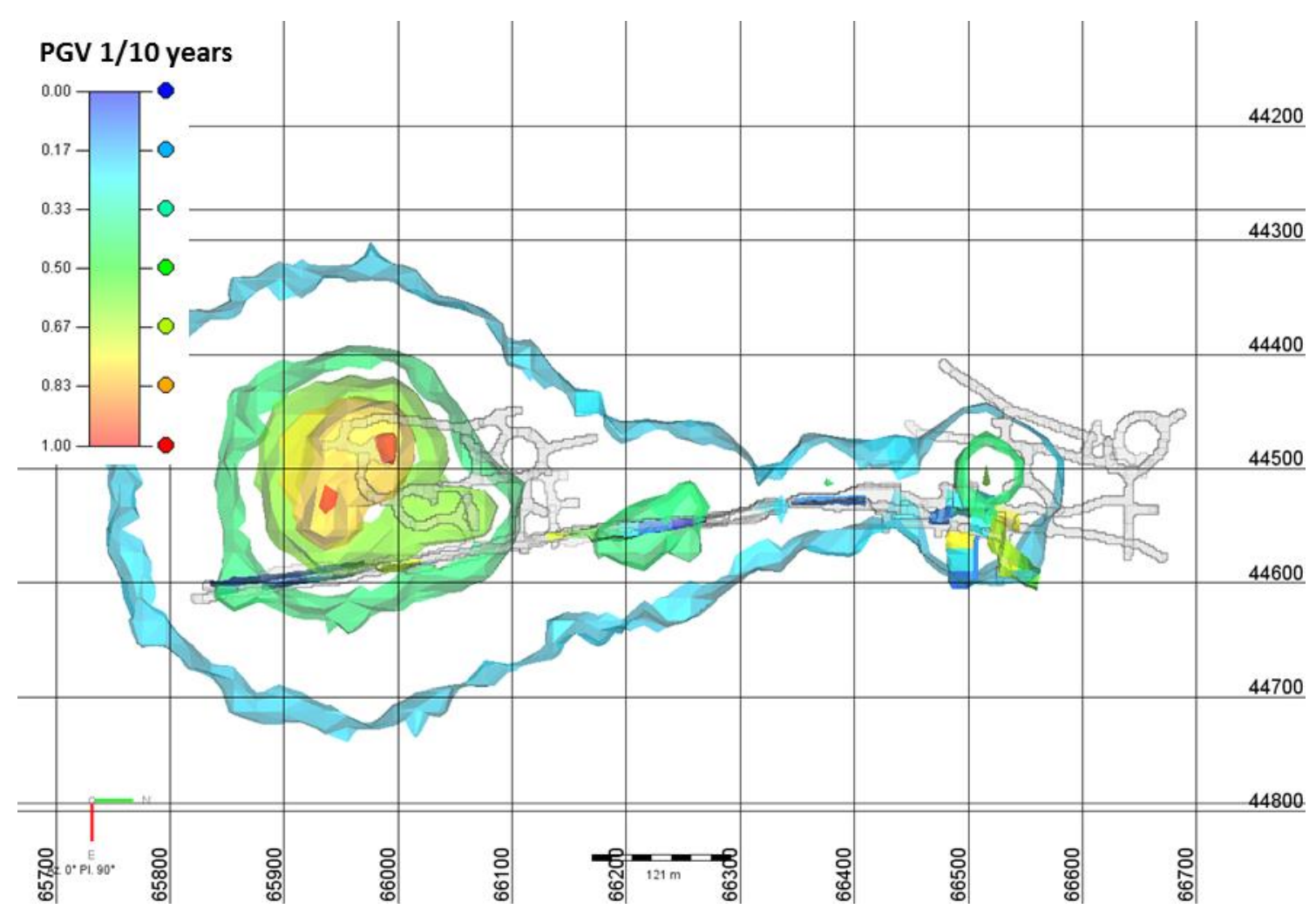

Figure 19 Ground motion hazard

\section{$4 \quad$ Concluding remarks}

The risk-based design process is applicable under high stress conditions, it takes into account geotechnical uncertainty. The understanding of aleatory variability can be improved by collecting more data and improving the quality of data through training and quality control. Stress and model uncertainty remain a challenge in geotechnical engineering. Some degree of subjective engineering judgement will therefore always be required in geotechnical design.

When determining 'acceptable probabilities of failure' for design it is necessary to evaluate the risk. The potential financial losses associated with stress damage will differ for different types of excavation. An economic model is a useful tool for risk evaluation. Risk matrices used on mining operations assist with the practical interpretation of risk.

The relative frequency approach is used by the insurance industry, where large amounts of data are available and it is possible to assess the potential risk quite reliably. In geotechnical engineering, it is appropriate to incorporate a subjective degree of belief approach. Where good data is available, this will improve confidence in the outcome and the degree of belief, but the interpretation will remain subjective.

\section{Acknowledgement}

The development of methods for risk-based design forms part of an industry funded research project entitled 'Ground Support Systems Optimisation', which is being led by the Australian Centre for Geomechanics. Major sponsors: Glencore Mount Isa Mines, Independence Group NL, Codelco Chile, MMG Limited, Minerals Research Institute of Western Australian, and the Australian Centre for Geomechanics. Minor sponsors: Jennmar Australia, Dywidag-Systems International Pty Ltd, Fero Strata Australia, Golder Associates Pty Ltd, Geobrugg Australia Pty Ltd, Atlas Copco Australia Pty Limited. Johan Wesseloo, Joseph Muaka, Philani Mpunzi and Denisha Sewnun made significant contributions to this work.

IvanPlats Ltd kindly provided permission to use rock mass characterisation and strength data for the fictitious case studies. 
Advice and guidance on the approach was provided by Luis-Fernando Contreras, Michael Dunn, Dick Stacey, Shaun Murphy, Jeanne Walls and Robert Armstrong.

The management of Renison mine are gratefully acknowledged for permission to publish seismic hazard data. Michael Dunn, Louie Human and Kevin Stacey were also involved in the dynamic support design process.

\section{References}

Abdellah, W, Mitri, HS \& Thibodeau, D 2014, 'Risk indexing tool for mine planning', Journal of the Southern African institute of Mining and Metallurgy, vol. 114, pp. 435-443.

Baecher, GB \& Christian, JT 2003, Reliability and Statistics in Geotechnical Engineering, John Wiley \& Sons, Ltd.

Bradley, N 2007, The Response Surface Methodology, Master's thesis, Indiana University South Bend.

Brown, ET 2012, 'Risk assessment and management in underground rock engineering-an overview', Journal of Rock Mechanics and Geotechnical Engineering, vol. 4, no. 3, pp. 193-204, viewed 30 January 2017, http://pub.chinasciencejournal.com/article/ getArticleRedirect.action?doiCode=10.3724/SP.J.1235.2012.00193

Chiwaye, HT \& Stacey, TR 2010, 'A comparison of limit equilibrium and numerical modelling approaches to risk analysis for open pit mining', Journal of the Southern African institute of Mining and Metallurgy, vol. 110, no. 10, pp. 571-580.

Christian, JT \& Baecher, GB 1999, 'Point-estimate method as numerical quadrature', Journal of Geotechnical and Geoenvironmental Engineering, vol. 125, pp. 779-786, viewed 30 January 2017, http://ascelibrary.org/doi/abs/10.1061/(ASCE) 1090-0241(1999)125:9(779)

Christian, JT \& Baecher, GB 2002, 'The point estimate method with large numbers of variables', International Journal for Numerical and Analytical Methods in Geomechanics, vol. 26, pp. 1,515-1,529, viewed 30 January 2017, http://onlinelibrary.wiley.com/ doi/10.1002/nag.256/abstract

Contreras, LF 2015 'An economic risk evaluation approach for pit slope optimization', Journal of the Southern African Institute of Mining and Metallurgy, vol. 115, no. 7, pp. 607-622.

Contreras, LF \& Ruest, M 2016, 'Unconventional methods to treat geotechnical uncertainty in slope design', in P Dight (ed.), Proceedings of the First Asia Pacific Slope Stability in Mining Conference, Australian Centre for Geomechanics, Perth, pp. 1-16.

Hadjigeorgiou, J \& Harrison, JP 2011, 'Uncertainty and sources of error in rock engineering', in Y Zhou (ed.), ISRM 12th International Congress on Rock Mechanics, International Society for Rock Mechanics, Lisboa, pp. 2,063-2,067, viewed 30 January 2017, https://www.onepetro.org/conference-paper/ISRM-12CONGRESS-2011-377\%5Cnpapers3://publication/uuid/59784E59-72 68-4618-B43E-C0819D1CAAD7

Harr, ME 1996, Reliability-based Design in Civil Engineering, Dover Publications Inc., New York.

Harris, P \& Wesseloo, J 2015, mXrap, Australian Centre for Geomechanics, Perth, www.mxrap.com

Hoek, E, Carranza-Torres, C \& Corkum, B 2002, 'Hoek-Brown failure criterion - 2002 edition', in R Hammah (ed.), Proceedings of the 5th North American Rock Mechanics Symposium and the 17th Tunnelling Association of Canada Conference, University of Toronto, Toronto, pp. 267-273.

Hoek, E, Carter, TG \& Diederichs, MS 2013, 'Quantification of the geological strength index chart', Proceedings of the 47th US Rock Mechanics/Geomechanics Symposium, American Rock Mechanics Association, Alexandria, ARMA 13-672.

Joughin, WC, Swart, A \& Wesseloo, J 2000, 'Risk based chromitite pillar design - Part II, non-linear modelling', Proceedings of the South African National Institute of Rock Engineers Symposium, South African National Institute of Rock Engineering, Rustenburg, pp. 8.

Joughin, WC, Muaku, JJM \& Wessleoo, J 2016, 'A risk-based approach to ground support design', in E Nordlund, TH Jones \& A Eitzenberger (eds), Proceedings of the Eighth International Symposium on Ground Support in Mining and Underground Construction, Luleå University of Technology, Luleå, Sweden, pp. 1-20.

Joughin, WC, Jager, A, Nezomba, E \& Rwodzi, L 2012 'A risk evaluation model for support design in Bushveld Complex underground mines: Part I - Description of the model', Journal of The Southern African Institute of Mining and Metallurgy, vol. 112, no. 2, pp. 83-94.

Kaiser, PK, McCreath, DR \& Tannant, D 1995, Rockburst Support Handbook, Geomechanics Research Centre, Laurentian University, Sudbury, Ontario.

Kroese, D \& Rubinstein, R 2012, 'Monte Carlo methods', Wiley Interdisciplinary Reviews: Computational Statistics, vol. 4, no. 1, pp. 48-58.

Langford, J \& Diederichs, M 2015, 'Reliable support design for excavations in brittle rock using a global response surface method', Rock Mechanics and Rock Engineering, vol. 48, pp. 669-689.

Linkov, AM 2005 'Numerical modeling of seismic and aseismic events in geomechanics', Journal of Mining Science, vol. 41, no. 1, pp. 14-26.

Lü, Q, Chan, C \& Low, B 2012, 'Probabilistic evaluation of ground-support interaction for deep rock excavation using artificial neural network and uniform design', Tunnelling and Underground Space Technology, vol. 32, pp. 1-18.

Lü, Q \& Low, BK 2011a 'Probabilistic analysis of underground rock excavations using response surface method and SORM', Computers and Geotechnics, vol. 38, no. 8, pp. 1,008-1,021, viewed 30 January 2017, http://linkinghub.elsevier.com/retrieve/ $\mathrm{pii} / \mathrm{S} 0266352 \times 11001078$ 
Lü, Q \& Low, BK 2011b 'Probabilistic analysis of underground rock excavations using response surface method and SORM', Computers and Geotechnics, vol. 38, no. 8, pp. 1,008-1,021, viewed 30 January 2017, http://linkinghub.elsevier.com/retrieve/ $\mathrm{pii} / \mathrm{S} 0266352 \times 11001078$

Malovichko, DA 2017 'Assessment and testing of seismic hazard for planned mining sequences', in J Wesseloo (ed.), Proceedings of the Eighth International Conference on Deep and High Stress Mining, 28-30 March 2017, Perth, Australian Centre for Geomechanics, Perth, in press.

Malovichko, DA \& Basson, G 2014 'Simulation of mining-induced seismicity using Salamon-Linkov method', in M Hudyma \& Y Potvin (eds), Proceedings of the Seventh International Seminar on Deep and High Stress Mining, 16-18 September 2014, Sudbury, Australian Centre for Geomechanics, Perth, pp. 667-680.

Marinos, P \& Hoek, E 2000, 'GSI: A geologically friendly tool for rock mass strength estimation', Proceedings of GeoEng2000: An International Conference on Geotechnical and Geological Engineering, Technomic Publishing Co., Lancaster, pp. 1422-1442.

Marinos, V, Marinos, P \& Hoek, E 2005, 'The geological strength index: Applications and limitations', Bulletin of Engineering Geology and the Environment, vol. 64, no. 1, pp. 55-65.

Rosenblueth, E 1975, 'Point estimates for probability moments', Proc. Nt. Acad. Sci. USA Vol. 72, No 10. pp 3812-3814.

Rosenblueth, E 1981, 'Two-point estimates in probabilities', Applied Mathematical Modelling, vol. 5, no. 5, pp. 329-335, viewed 30 January 2017, http://linkinghub.elsevier.com/retrieve/pii/S0307904X81800546

Ryder, JA \& Jager, AJ 2002, A Textbook on Rock Mechanics for Tabular Hard Rock Mines, The Safety in Mines Research Advisory Committee (SIMRAC), Braamfontein.

Salamon, M 1993, 'Keynote address: Some applications of geomechanical modelling in rockburst and related research', in RP Young (ed.), Proceedings of the 3rd International Symposium on Rockbursts and Seismicity in Mines, AA Balkema, Rotterdam, pp. 297-309.

Steffen, OKH, Contreras, LF, Terbrugge, PJ \& Venter, J 2008, 'A Risk Evaluation Approach for Pit Slope Design', in The 42nd U.S. Rock Mechanics Symposium, USRMS, 29 June-2 July 2008, San Francisco, California, American Rock Mechanics Association.

Tapia, A, Contreras, LF, Jefferies, M \& Steffen, O 2007, 'Risk evaluation of slope failure at the Chuquicamata mine', in Y Potvin (ed.), Proceedings of the 2007 International Symposium on Rock Slope Stability in Open Pit Mining and Civil Engineering, 12-14 September 2007, Perth, pp. 477-495, viewed 30 January 2017, http://scholar.google.com/scholar?hl=en\&btnG= Search\&q=intitle:Risk+Evaluation+of+Slope+Failure+at+the+Chuquicamata+Mine\#0

Terbrugge, PJ, Wesseloo, J, Venter, J \& Steffen, OKH 2006 'A risk consequence approach to open pit slope design', Journal of the Southern African Institute of Mining and Metallurgy, vol. 106, no. 7, pp. 503-511.

Valley, B, Kaiser, P \& Duff, D 2010, 'Consideration of uncertainty in modelling the behaviour of underground excavations', in M Van Sint Jan \& Y Potvin (eds), Proceedings of the Fifth International Seminar on Deep and High Stress Mining, Australian Centre for Geomechanics, Perth, pp.423-435.

Vick, S, 2002 Degrees of Belief - Subjective Probability and Engineering Judgment, American Society of Civil Engineers Press, Reston, Virginia.

Wesseloo, J 2016, 'The use of elastic superposition as part of a multi-tiered probabilistic ground support design approach', in E Nordlund, TH Jones \& A Eitzenberger (eds), Proceedings of the Eighth International Symposium on Ground Support in Mining and Underground Construction, Luleå University of Technology, pp. 1-9.

Wesseloo, J, 2013, 'Towards real-time probabilistic hazard assessment of the current hazard state for mines', Proceedings of the Eighth International Symposium on Rockbursts and Seismicity in Mines, Geophysical Survey of Russian Academy of Sciences, Obninsk, Mining Institute of the Ural Branch of the Russian Academy of Sciences, A Malovichko and D Malovichko (eds), Perm, pp. 307-312.

Wesseloo, J \& Read, J 2009, 'Acceptance Criteria', in P Stacey \& J Read (eds), Guidelines for Open Pit slope Design, Commonwealth Scientific and Industrial Research Organisation Publishing, Collingwood, pp. 221-236.

Wiles, T 2016, Map3D Fault Slip, Map3D International Ltd, www.map3d.com 
